\title{
Incidence and outcomes of cases of caesarean scar ectopic pregnancy in a tertiary referral centre
}

\author{
E-S E-B Mohamed, PhD; E A Abdel Fattah, PhD; S T El Kemary, MD; T M Abdel Dayem, PhD
}

Obstetrics and Gynecology Department, Faculty of Medicine, Alexandria University, Egypt

Corresponding author: T Abdel Dayem (tmdaeim@gmail.com)

\begin{abstract}
Background. Caesarean scar ectopic pregnancy (CSEP) is a rare condition in which the implantation of the gestational sac takes place within the uterine scar of a previous caesarean section (CS). If the pregnancy continues within the uterus, the risk of placenta accrete or uterine rupture is increased.

Objective. To investigate four treatment methods, based on each patient's clinical presentation, gestational age of the pregnancy and haemodynamic stability, for the management of CSEP.

Methods. CSEP cases $(N=30)$ were diagnosed by ultrasound at the Shatby Maternity University Hospital, Egypt. Various treatment modalities, based on gestational age, were employed to treat the patients. Treatments included suction curettage $(n=12)$, embryo reduction with local methotrexate injection $(n=12)$, laparoscopic excision $(n=3)$ and excision through laparotomy $(n=3)$. Serum levels of beta-human chorionic gonadotrophin ( $\beta$-hCG) were measured at diagnosis and weekly following treatment until the levels returned to non-pregnant values.

Results. There was a significant positive correlation between gestational age in weeks and the CSEP management strategy employed. $\beta$-hCG levels decreased from before treatment to the end of the follow-up period 3 weeks later. No cases required a hysterectomy, and no maternal complications were reported in this study.

Conclusion. The appropriate CSEP management strategy varies according to gestational age. Suction and embryo reduction with local methotrexate injection offers an effective, safe and minimally invasive surgical treatment to remove ectopic pregnancy tissue. Closely monitored follow-up of patients, including serial measurement of $\beta$-hCG levels and ultrasonographic examinations, is recommended after CSEP management.
\end{abstract}

S Afr J Obstet Gynaecol 2020;26(1):18-21. https://doi.org/10.7196/SAJOG.2020.v26i1.1520

Caesarean scar ectopic pregnancy (CSEP) is a rare condition in which the implantation of the gestational sac takes place within the uterine scar of a previous caesarean section (CS). As a result, the gestation of a CSEP is located within the area surrounded by the myometrium and fibromuscular tissue of the scar. ${ }^{[1,2]}$ The pathogenesis has not been delineated. However, the prominent theory is that impaired wound healing after previous trauma, such as after CS or myomectomy, creates a myometrial defect and a subsequent scar at which the blastocyst implants. ${ }^{[3,4]}$

The most common CSEP presentations are asymptomatic and discovered by ultrasonography, painless vaginal bleeding due to rupture towards the cavity or generalised abdominal pain caused by rupture through the uterine serosa. If the pregnancy continues within the uterus, the risk of placenta accreta or ruptured uterus is increased. ${ }^{[5]}$ CSEPs are associated with lifethreatening complications, including scar rupture, haemorrhage and disseminated intravascular coagulation, which may require a lifesaving hysterectomy. ${ }^{[6]}$ Numerous approaches have been described to treat individuals with CSEP, including suction curettage, embryo reduction together with a local methotrexate injection, or abdominal, laparoscopic or hysteroscopic resection of the gestational tissue. ${ }^{[7]}$ The management strategy should be tailored according to each patient's clinical presentation, the gestational age of the pregnancy and the patient's haemodynamic stability. ${ }^{[7]}$

Uterine suction curettage is performed under general anaesthesia and involves the insertion of the suction curette into the uterus through the dilated cervix, where it is used to scrape the lining of the uterus and remove the pregnancy tissue under guidance by perioperative transabdominal or transrectal ultrasound scan. ${ }^{[8]}$

Transvaginal ultrasound-guided local methotrexate treatment may be considered as a first-line treatment. ${ }^{[9]}$ Methotrexate can be given intramuscular or locally into the gestational sac. The criteria for administration of systemic methotrexate for ectopic pregnancy are a gestational age of $<8$ weeks, absent fetal cardiac activity, a haemodynamically stable patient, beta-human chorionic gonadotrophin ( $\beta$-hCG) serum level of $<12000 \mathrm{mIU} / \mathrm{mL}$ and $>2 \mathrm{~mm}$ thickness between the myometrium and bladder. ${ }^{[10]}$ Embryo reduction plus local methotrexate injection is performed under general anaesthesia using a double lumen oocyte pick-up needle, which is introduced into the gestational sac under transvaginal ultrasound guidance and used to mechanically disrupt the pregnancy. ${ }^{[9]}$ The use of local methotrexate treatment alone or in conjunction with suction curettage can potentially avoid unnecessary laparotomy and preserve fertility in most women with CSEP. ${ }^{[1]}$ Additional surgical or medical management are considered if the CSEP does not resolve with the initial methotrexate treatment. ${ }^{[3]}$

Laparotomy can be used when performing a myometrial wedge excision or complete hysterectomy. It has a high success rate, but it is not deemed a first-line treatment due to potential patient morbidity, the invasive nature of the procedure, longer operating time, ureter and/or bladder injuries, intraoperative blood loss, longer duration of hospital stay, wound complications and a slower return to normal activity. ${ }^{[12]}$ 
Laparoscopic hysterotomy with wedge resection of the CSEP and previous scar has been reported in several studies. This approach has been recommended for patients with CSEP growing toward the bladder or abdominal wall. ${ }^{[3,13]}$ The trophoblastic mass plays an important role in defining the risk of conversion from medical to surgical treatment. ${ }^{[14]}$ Surgical treatment, including ultrasoundguided evacuation, ${ }^{[15]}$ is considered as a rapid and successful resolution of CSEP. ${ }^{[16]}$

\section{Objective}

To investigate four methods of treating cases diagnosed with CSEP at a tertiary referral center in Alexandria, Egypt.

\section{Methods}

This study was approved by the ethics committee of the Faculty of Medicine, University of Alexandria (ref. no. 00012098) and conducted at the Shatby Maternity University Hospital, Egypt. The study cohort comprised 30 women diagnosed with CSEP, based on a transvaginal ultrasound (GE Voluson P8 Ultrasound), between May 2016 and April 2019.

Ultrasonographic criteria for CSEP diagnosis were: ${ }^{[16]}$

(i) empty uterine cavity, with clearly demonstrated endometrium;

(ii) a clearly visible empty cervical canal, without contact with the gestational sac; and

(iii) presence of the gestation sac with (or without) a fetal pole with (or without) fetal cardiac activity (depending on the gestational age) in the anterior part of the uterine isthmus.

Patients were informed about emergency conditions, including excessive bleeding and severe pain, and were monitored as outpatients following treatment.

Different CSEP treatment modalities, according to gestational age, were used in this study. Briefly, cases presenting before 6 weeks' gestation were treated using suction curettage under ultrasonographic guidance, while those presenting after 6 - 8 weeks' gestation were treated using suction curettage or embryo reduction and local methotrexate injection, according to the patient's choice after counselling and explaining the two different methods of treatment. Cases presenting with an acute abdomen, moderate or severe vaginal bleeding were treated by laparotomy or laparoscopy.

Measurement of $\beta$-hCG serum levels was performed at diagnosis using a chemiluminescence assay, ${ }^{[17]}$ and every week after CSEP management until the levels returned to non-pregnant values $(<5 \mathrm{mIU} / \mathrm{mL})$.

Data were analysed using SPSS version 20 (IBM Corp., USA) and a $p$-value $<0.05$ was considered statistically significant. Qualitative data were described using number and percentage, while quantitative data were described using range (minimum and maximum), mean and standard deviation (SD). $\chi^{2}$ tests were used for categorical variables and a Monte Carlo (MC) correction applied for $\chi^{2}$ when more than $20 \%$ of the cells had an expected count $<5$.

\section{Results}

In this study, CSEP cases $(N=30)$ were diagnosed by transvaginal ultrasound (Fig. 1). The number of previous CS within this cohort ranged from 1 - 5, with a mean of 2.5 previous CS, and the majority (40\%) of the women had previously had 3 CS (Table 1). The number of years since last delivery in these patients ranged from 1 - 7, with a mean (SD) of 2.8 (1.42) years. The women had a mean (SD) gestational age at diagnosis of 7.01 (1.13) weeks, and this determined the respective management strategies (Table 2). Haemodynamically stable patients were treated by suction curettage $(n=12)$ for those diagnosed at a gestational age of $<8$ weeks, while embryo reduction and local methotrexate injection were used to treat patients $(n=12)$ diagnosed at a gestational age of $\geq 6$ weeks. Patients diagnosed at a gestational age of $>8$ weeks were managed by either laparoscopic excision $(n=3)$ or laparotomy $(n=3)$. Patients treated by laparoscopy presented with abdominal pain and signs of peritoneal irritation and were haemodynamically stable. Those patients treated by laparotomy showed signs of peritoneal irritation, with a maternal heart rate above 120 beats per minute, and ultrasonographic evidence of moderate peritoneal collection.

As an indicator of ectopic pregnancy, $\beta$-hCG serum levels were quantified at diagnosis, and then again at outpatient follow-ups 1 and 3 weeks after CSEP treatment (Table 3). The mean baseline level of $\beta$-hCG decreased significantly 1 week after treatment. The mean (SD) $\beta$-hCG levels decreased to $2.32(1.48) \mathrm{mIU} / \mathrm{mL} 3$ weeks after treatment. Overall, there was a significant positive correlation between $\beta$-hCG levels for the four management strategies, following treatment.

The use of suction and embryo reduction with local methotrexate injection offers an effective, safe and minimally invasive surgical treatment to remove ectopic pregnancy tissue (Fig. 2). CSEP management by suction curettage was observed to result in the slowest reduction of $\beta$-hCG serum levels within the first week following treatment.

\section{Discussion}

Since the first reported case in $1978,{ }^{[18]}$ an increasing number of CSEP cases have been reported, and this is thought to be correlated with an increased rate of caesarean deliveries. ${ }^{[19]}$ Harb et al. ${ }^{[15]}$

\begin{tabular}{ll}
\multicolumn{2}{l}{ Table 1. Number of previous CS in the studied women } \\
\hline Previous CS & $\boldsymbol{n}(\%)$ \\
\hline 1 & $4(13.3)$ \\
2 & $8(26.7)$ \\
3 & $12(40.0)$ \\
4 & $4(13.3)$ \\
5 & $2(6.7)$
\end{tabular}

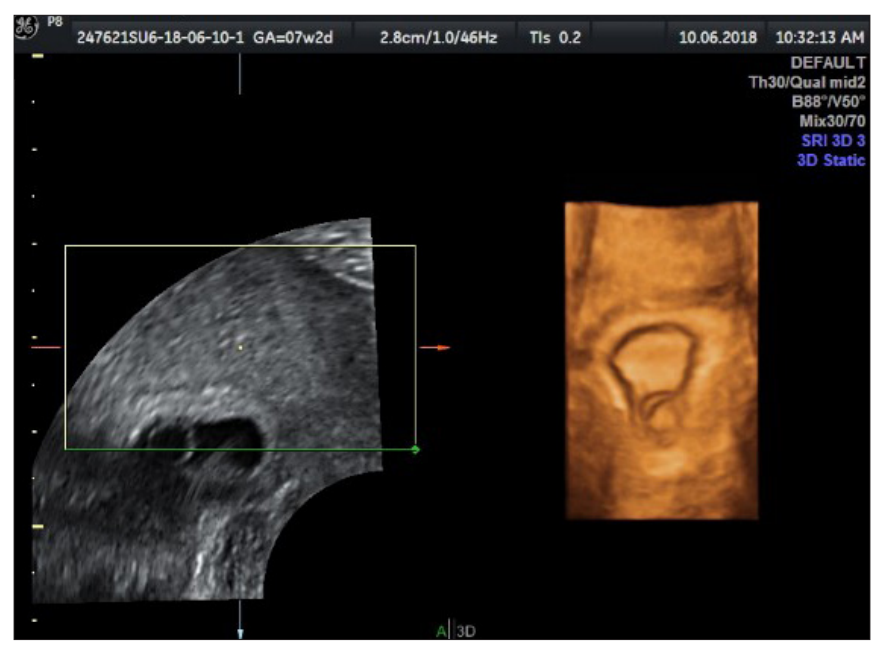

Fig. 1. Ultrasonogram, $2 D$ (left) and $3 D$ (right), of one case from the study cohort who was diagnosed at a gestational age of 6 weeks, before treatment. 
estimated the incidence of CSEP across 86 early pregnancies from 2013 to 2015 to be 1.5 per 10000 pregnancies in the UK. In contrast, Shatby Maternity University Hospital has a high incidence of CSEP as a proportion of all ectopic pregnancies. The estimated incidence at Shatby Maternity University Hospital is 1 per 2100 pregnancies, and 10 per 100 ectopic pregnancies. The elevated CSEP frequency may be attributed to a high ( 52\% in 2014) and increasing CS rate in Egypt. ${ }^{[20]}$ Furthermore, Shatby Maternity University Hospital is a tertiary referral hospital, for an area with a population of 15 million, and most tubal ectopic pregnancies are managed in secondary referral hospitals.

Maymon et al. ${ }^{[21]}$ and Jurkovic et al. ${ }^{[16]}$ reported that 50 and $72 \%$, respectively, of CSEP patients within their studies had previously undergone multiple CS. Poor healing after two or more CS could contribute to the elevated risk of CSEP. In the current study, $86.7 \%$ of patients had previously had two or more CS. A wide variation in the median interval between the last caesarean delivery and CSEP, from 2 months to 17 years, has been previously reported, and this suggests that the risk of CSEP is not reduced by increased duration since last caesarean delivery. ${ }^{[2]}$

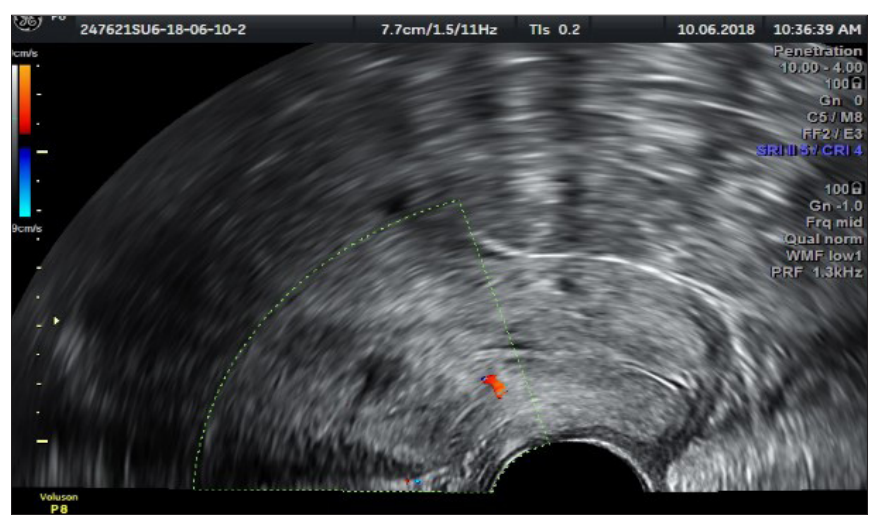

Fig. 2. A 2D ultrasonogram of a patient from the study cohort 3 weeks after successful CSEP treatment by embryo reduction and local methotrexate injection.
In the present study, only $20 \%$ of the patients presented with symptoms of lower abdominal pain and vaginal bleeding. This is in agreement with previous studies in which the majority of patients were asymptomatic and diagnosed incidentally while having an early pregnancy ultrasound. ${ }^{[14,16]}$

In the current study, the CSEP management strategy was planned according to gestational age in weeks. All 5 cases presenting before 6 weeks' gestation were treated by ultrasound-guided suction curettage. A further 17 cases presented between 6 and 8 weeks' gestation, and these were managed according to the patient's choice after counselling. Briefly, 10 patients were treated by embryo reduction and local methotrexate injection, and 7 were treated by ultrasound-guided suction curettage. Eight cases presented after 8 weeks' gestation, and 2 of these cases were treated by embryo reduction and local methotrexate injection, while 6 cases were treated either by laparoscopy or laparotomy due to signs of disturbed pregnancy.

In the current study, mean (SD) serum $\beta$-hCG levels decreased significantly over the course of the 3 -week period following treatment, to $2.32(1.48) \mathrm{mIU} / \mathrm{mL}$. The slowest reduction in $\beta$-hCG levels was observed for the suction management group, possibly due to incomplete removal of trophoblastic tissue from the uterus during suction evacuation, as compared with the patients treated by embryo reduction with local methotrexate injection. This could be complemented by a dose of methotrexate if $\beta$-hCG levels continue to persist. $\beta$-hCG levels decreased rapidly in both the laparotomy and laparoscopic treatment groups. These findings are in agreement with previous studies that reported successful CSEP treatment outcomes associated with a $>15 \%$ decline in $\beta$-hCG levels within a week, and reaching undetectable levels a month after treatment. ${ }^{[22]} \mathrm{He}$ et al. ${ }^{[23]}$ in a study of 6 patients following successful vaginal treatment for CSEP, reported that serum $\beta$-hCG levels reached undetectable levels after 1 month of treatment.

\section{Conclusion}

CSEP is an important phenomenon in modern obstetrics. Early diagnosis enables the use of minimally invasive methods of

Table 2. The CSEP management strategy according to gestational age

\begin{tabular}{|c|c|c|c|c|c|c|}
\hline \multirow[b]{2}{*}{ GA (weeks) } & \multicolumn{4}{|c|}{ Management strategy } & \multirow[b]{2}{*}{$x^{2}$} & \multirow[b]{2}{*}{ MCp } \\
\hline & $\begin{array}{l}\text { Suction evacuation } \\
(N=12), n(\%)\end{array}$ & $\begin{array}{l}\text { Embryo reduction and local } \\
\text { methotrexate injection } \\
(N=12), n(\%)\end{array}$ & $\begin{array}{l}\text { Laparotomy } \\
(N=3), n(\%)\end{array}$ & $\begin{array}{l}\text { Laparoscopic excision } \\
(N=3), n(\%)\end{array}$ & & \\
\hline$<6$ & $5(41.7)$ & $\mathrm{n} / \mathrm{a}$ & $\mathrm{n} / \mathrm{a}$ & $\mathrm{n} / \mathrm{a}$ & & \\
\hline $6-8$ & $7(58.3)$ & $10(83.3)$ & $\mathrm{n} / \mathrm{a}$ & $\mathrm{n} / \mathrm{a}$ & $22.279^{*}$ & $<0.001^{\star}$ \\
\hline$>8$ & $\mathrm{n} / \mathrm{a}$ & $2(16.7)$ & $3(100)$ & $3(100)$ & & \\
\hline
\end{tabular}

Table 3. The mean $\beta$-hCG levels pre and post treatment for the respective management strategies

\begin{tabular}{|c|c|c|c|c|}
\hline \multirow[b]{3}{*}{ Management strategy } & \multicolumn{4}{|c|}{$\beta$-hCG levels (mIU/mL) } \\
\hline & \multirow[b]{2}{*}{$\begin{array}{l}\text { Pre-treatment }(n=30) \text {, } \\
\text { mean }(S D)\end{array}$} & \multicolumn{2}{|c|}{ Post-treatment } & \multirow[b]{2}{*}{$p$-value } \\
\hline & & $\begin{array}{l}1 \text { week }(n=20) \text {, } \\
\text { mean }(S D)\end{array}$ & $\begin{array}{l}3 \text { week }(n=16) \text {, } \\
\text { mean }(S D)\end{array}$ & \\
\hline Suction curettage $(n=12)$ & $15183(15417.2)$ & $5758(5438)$ & $3(2)$ & $0.0001^{\star}$ \\
\hline Embryo reduction and local methotrexate injection $(n=12)$ & $20836(11208)$ & $4197(4667)$ & $2(1)$ & $0.0001^{*}$ \\
\hline Laparoscopic excision $(n=3)$ & $20206(9813.0)$ & $3123(2502)$ & $4(1)$ & $0.001^{*}$ \\
\hline Laparotomy $(n=3)$ & $27970(7938.3)$ & $1660(1027)$ & $3(1)$ & $0.001^{*}$ \\
\hline
\end{tabular}


treatment. Embryo reduction plus local methotrexate injection appears to offer an effective and minimally invasive surgical treatment option to remove ectopic pregnancy tissue until 8 weeks' gestation, while more invasive methods are needed after 8 weeks' of gestation. Given the risk of remote complications and a potential need for additional treatment modalities, follow-up with serial measurement of quantitative $\beta$-hCG levels and serial ultrasonographic examinations are recommended.

Declaration. None.

Acknowledgements. None.

Author contributions. Cases were diagnosed and treated by all authors. Data were collected by SEK. The manuscript was written by TAD. All authors approved the final version of the manuscript.

Funding. The authors would like to thank the University of Alexandria, Egypt, for financial support.

Conflicts of interest. None.

1. Pędraszewski P, Wlaźlak E, Panek W, Surkont G. Cesarean scar pregnancy - a new challenge for obstetricians. J Ultrason 2018;18(72):56-62. https://doi.org/10.15557/jou.2018.0009

2. Le A, Shan L, Xiao T, Zhuo R, Xiong H, Wang Z. Transvaginal surgical treatment of cesarean sca ectopic pregnancy. Arch Gynecol Obstet 2013;287(4):791-796. https://doi.org/10.1007/s00404012-2617-7

3. Gonzalez N, Tulandi T. Cesarean scar pregnancy: A systematic review. J Minim Invasive Gynecol 2017;24(5):731-738. https://doi.org/10.1016/j.jmig.2017.02.020

4. Li Y, Gong L, Wu X, Gao H, Zheng H, Lan W. Randomized controlled trial of hysteroscopy or ultrasonography versus no guidance during $\mathrm{D} \& \mathrm{C}$ after uterine artery chemoembolization for cesarean scar pregnancy. Int J Gynaecol Obstet 2016;135(2):158-162. https://doi.org/10.1016/j. ijgo.2016.04.019

5. Carusi D. Placenta accreta: Epidemiology and risk factors. In: Silver RM, ed. Placenta Accreta Syndrome. Boca Raton: CRC Press, 2017:1-12.

6. Collins K, Kothari A. Catastrophic consequences of a caesarean scar pregnancy missed on ultrasound. Australia J Ultrasound Med 2015;18(4):150-156. https://doi.org/10.1002\%2Fj.2205-0140.2015.tb00222.x
7. Maheux-Lacroix S, Li F, Bujold E, Nesbitt-Hawes E, Deans R, Abbott J. Cesarean scar pregnancies: A systematic review of treatment options. J Minim Invasive Gynecol 2017;24(6):915-925. https:// doi.org/10.1016/j.jmig.2017.05.019

8. Weilin C, Li J. Successful treatment of endogenous cesarean scar pregnancies with transabdominal ultrasound-guided suction curettage alone. Eur J Obstet Gynecol Reprod Biol 2014;183:20-22.

9. Cok T, Kalayci H, Ozdemir H, Haydardedeoglu B, Parlakgumus AH, Tarim E. Transvaginal ultrasoundguided local methotrexate administration as the first-line treatment for cesarean scar pregnancy: Follow-up of 18 cases. J Obstet Gynaecol Res 2015;41(5):803-808. https://doi.org/ 10.1111/jog.12627

10. Wang JH, Xu KH, Lin J, Xu JY, Wu RJ. Methotrexate therapy for cesarean section scar pregnancy with and without suction curettage. Fertil Steril 2009;92(4):1208-1213.

11. Liu G, Wu J, Cao J, et al. Comparison of three treatment strategies for cesarean scar pregnancy Arch Gynecol Obstet 2017;296(2):383-389. https://doi.org/10.1007/s00404-017-4426-5

12. Ong X, Mathur M, Kew C, Chern B. Surgical management of cesarean scar pregnancies - a single tertiary experience. Gynecol Minim Invasive Ther 2014;3(3):82-88.

13. Le A, Li M, Xu Y, et al. Different surgical approaches to 313 cesarean scar pregnancies. J Minim Invasive Gynecol 2019;26(1):148-152. https://doi.org/10.1016/j.jmig.2018.03.035

14. Dior UP, Palma-Dias R, Reidy KL, Cheng C, Healey M. Cesarean scar pregnancies: Incidence and factors associated with conversion to surgery from medical management. J Minim Invasive Gynecol 2019;26(5):919-927. https://doi.org/10.1016/j.jmig.2018.09.771

15. Harb HM, Knight M, Bottomley C, et al. Caesarean scar pregnancy in the UK: A national cohort study. Br J Obstet Gynaecol 2018;125(13):1663-1670. https://doi.org/10.1111/1471-0528.15255

16. Jurkovic D, Hillaby K, Woelfer B, Lawrence A, Salim R, Elson CJ. First-trimester diagnosis and management of pregnancies implanted into the lower uterine segment cesarean section scar. Ultrasound Obstet Gynecol 2003;21(3):220-227. https://doi.org/10.1002/uog.56

17. Oed M, Amtmann R, Löwer Y, Schlett R, Mack M. LIAISON hCG - an automated chemiluminescent immunoassay for the determination of human chorionic gonadotropin (hCG). Anticancer Res 1999;19(4):2735-2737.

18. Larsen JV, Solomon MH. Pregnancy in a uterine scar sacculus - an unusual cause of postabortal haemorrhage. A case report. S Afr Med J 1978;53(4):142-143.

19. Timor-Tritsch IE, Monteagudo A. Unforeseen consequences of the increasing rate of cesarean deliveries: Early placenta accreta and cesarean scar pregnancy. A review. Am J Obstet Gyneco 2012;207(1):14-29. https://doi.org/10.1016/j.ajog.2012.03.007

20. Abdel-Tawab N, Oraby D, Hassanein N, El-Nakib S. Cesarean section deliveries in Egypt: Trends, practices, perceptions and costs. Cairo: The Population Council, 2018.

21. Maymon R, Halperin R, Mendlovic S, et al. Ectopic pregnancies in CS scars: The 8-year experience of one medical centre. Hum Reprod 2004;19(2):278-284. https://doi.org/10.1093/humrep/deh060

22. Sadeghi $\mathrm{H}$, Rutherford T, Rackow BW, et al. Cesarean scar ectopic pregnancy: Case series and review of the literature. Am J Perinatol 2010;27(2):111-120. https://doi.org/10.1055/s-0029-1224874

23. He M, Chen MH, Xie HZ, et al. Transvaginal removal of ectopic pregnancy tissue and repair of uterine defect for caesarean scar pregnancy. BJOG 2011;118(9):1136-1139.https://doi.org/ 10.1111/j.1471 0528.2011.02891.x

Accepted 5 April 2020. 